OPEN ACCESS

Edited by:

Mary Anne Sampaio Melo,

University of Maryland, Baltimore,

United States

Reviewed by:

Samira Camargo,

University of Florida, United States

Lamia Sami Mokeem,

University of Maryland, Baltimore,

United States

Jingwei He,

South China University of Technology,

China

*Correspondence:

Yuanhua Lin

linyh@mail.tsinghua.edu.cn

Specialty section: This article was submitted to Biomaterials,

a section of the journa

Frontiers in Materials

Received: 20 January 2021

Accepted: 09 March 2021

Published: 22 April 2021

Citation:

Cui $B$, Sun $F$, Ding $Q$, Wang $H$

Lin Y, Shen Y, Li M, Deng X, Zhang L

and Nan C (2021) Preparation

and Characterization of Sodium

Aluminum Silicate-Polymer

Composites and Effects of Surface

Roughness and Scratch Directions on

Their Flexural Strengths.

Front. Mater. 8:655156.

doi: 10.3389/fmats.2021.655156

\title{
Preparation and Characterization of Sodium Aluminum Silicate-Polymer Composites and Effects of Surface Roughness and Scratch Directions on Their Flexural Strengths
}

Bencang Cui', Fengbo Sun', Qian Ding', Huining Wang ${ }^{3}$, Yuanhua Lin ${ }^{1 *}$, Yang Shen', Ming Li' ${ }^{1}$, Xuliang Deng ${ }^{4,5}$, Lei Zhang' ${ }^{2}$ and Cewen Nan'

${ }^{1}$ State Key Laboratory of New Ceramics and Fine Processing, School of Materials Science and Engineering, Tsinghua University, Beijing, China, ${ }^{2}$ Department of Prosthodontics, School and Hospital of Stomatology, Peking University, Beijing, China, ${ }^{3}$ Department of Periodontics, School and Hospital of Stomatology, Institute of Stomatology, Wenzhou Medical University, Wenzhou, China, ${ }^{4}$ Department of Geriatric Dentistry, Peking University School and Hospital of Stomatology, Beijing, China, ${ }^{5}$ Department of Prosthodontics, Peking University School and Hospital of Stomatology, Beijing, China

Although efforts have been put into the research in polymer-infiltrated ceramic network composites (PICNs), data are needed to understand the relationship between surface roughness and flexural strength. In this work, a novel dental restorative composite was fabricated via infiltrating mixtures of Bis-GMA/TEGDMA and UDMA/TEGDMA into partially sintered porous sodium aluminum silicate blocks and curing. Bars with different surface conditions were produced by sanding with abrasive and polishing. Flexural strength was measured using three-point-bending. Scanning electron microscopy (SEM) was employed to observe the microstructure of surface areas. One-way analysis of variance was applied for statistical calculations, with $p<0.05$ being considered significant. Weibull plots were used to evaluate the reliability of flexural strength. The results demonstrated that the flexural strength of the resultant composites was affected by the scratch direction and the value of roughness. The flexural strength increased with decrease of surface roughness. A higher strength value was found for parallel types than for vertical types with nearly the same surface roughness. A large roughness value and a scratch direction perpendicular to tensile stress produced a low Weibull modulus. Of particular importance with this work is that these factors should be taken into consideration when using PICNs as dental restorative composites.

Keywords: polymer infiltrated ceramic network composites, mechanical properties, dental composites, CAD/CAM blocks, crack bridging

\section{INTRODUCTION}

Increased demand for dental restorative materials with high mechanical properties and esthetic performances leads to the extensive use of ceramics (Denry and Kelly, 2008; Miyazaki et al., 2013; Li et al., 2014) and composites (Moszner and Salz, 2001; Mitra et al., 2003; Klapdohr and Moszner, 2005; Ferracane, 2011; Acar et al., 2016; Alharbi et al., 2017). Ceramics possess excellent esthetic 
performance and high flexural strength, hardness, and elastic modulus in comparison with resin composites. However, the hardness and elastic modulus are so much higher than that of natural enamel and dentin, which lead to the wear of the natural tooth, such that these kinds of materials were even not suggested to be used in areas of crowns (Moszner and Salz, 2001; Mitra et al., 2003; Klapdohr and Moszner, 2005; Ferracane, 2011; Lawson et al., 2014; Acar et al., 2016; Alharbi et al., 2017). Furthermore, it is difficult to machine thoroughly sintered ceramics because of the ultra-high hardness.

Composites are classified into filled composites and polymerinfiltrated ceramic network composites (PICNs) according to processing characteristics. Filled composites are fabricated by adding inorganic particles to polymerizable monomers and curing. For filled composites, the polymer is continuous phase, while inorganic particles are dispersed into that phase (Klapdohr and Moszner, 2005). Early dental restorative composites were all filled composites. Because of low flexural strength, hardness, and modulus of filled composites, they are mainly used as adhesives and direct restorative materials. PICNs are prepared via infiltrating polymerizable monomers into porous ceramic networks (He and Swain, 2011; Swain et al., 2016). The corresponding porous ceramics are mainly partially sintered under a lower temperature and with a shorter holding time in case of the formation of dense ceramics. Differently from filled composites, PICNs are composed of two inter-penetrating phases, i.e., polymer and porous ceramic networks. The effects of the characteristics of inorganic particles and inorganic/organic ratios on mechanical properties have been thoroughly examined. The conclusion was that the hardness and elastic modulus of the resultant composites increased with the increase of inorganic particle loading.

Polymerization shrinkage and low degrees of conversion (DC) are two factors that limit the performance of direct restorative composite. As monomers are converted into polymers, covalent bonds are created from Van der Waals band causing a volume reduction. Reduction of DC and polymerization rate may be beneficial to decreasing polymerization shrinkage, but both have drawbacks. A low DC may cause a substantial compromise of mechanical properties (Ferracane and Greener, 1986). An effective approach is soft-start curing, hypothesized to decrease polymerization rate without compromising other properties (Rueggeberg, 2011). However, several studies showed that softstart curing often resulted in the reduction of mechanical properties (Feng and Suh, 2006; Silva Prezotto et al., 2018). Furthermore, the DC of light-cured direct restorative composites is low and decreases with increase of depth and addition of inorganic fillers (Aljabo et al., 2015).

With the developments of material process technology, high particle loading filled composites and PICNs were fabricated and launched by manufacturers. These composites are used as CAD/CAM blocks, the same as ceramics. Lava Ultimate (filled composites) and VITA ENAMIC (PICNs) were launched by $3 \mathrm{M}$ ESPE in 2012 and VITA in 2013, respectively (Thornton, 2014). The mechanical properties of PICNs are more similar to that of the natural tooth. Of particular significance will be to develop novel PICNs and their unique mechanical behaviors.
Dental materials are used in complex oral environments, so it is necessary to pay attention to the specific service state (real service state) and explore their properties accordingly. Though PICNs possess high flexural strength, the restoration could fail at an early age because of the developing roughness. The increasing roughness may be caused by insufficient polishing during restoration and by the wear in oral environment. However, little information is available about the effects of roughness and defect dimensions on the flexural strength of dental restorative composites. Therefore, knowledge about how surface roughness and scratch directions affect flexural strength is necessary to improve the usage of composites. Clinicians should take into consideration that PICNs may be susceptible to surface roughness and scratch directions perpendicular to tensile stress.

The null hypothesis was that surface roughness and defect direction have equally decreasing effects on the flexural strength of composites.

\section{MATERIALS AND METHODS}

\section{Materials}

The raw materials used in this study were sodium aluminum silicate (SIPERNAT 820A, Degussa AG, Germany), Bis-GMA, UDMA, TEGDMA (Aladdin Reagents Company, Shanghai, China), and BPO (J\&K Scientific, Ltd.).

\section{Specimen Preparation}

Sodium aluminum silicate powder was compressed into blocks using a steel mold $30 \mathrm{~mm}$ in diameter with a pressure of $3 \mathrm{MPa}$ and a holding time of $3 \mathrm{~min}$. Then, the blocks were subjected to isostatic cool pressing with a pressure of $220 \mathrm{MPa}$ and a stay time of $2 \mathrm{~min}$. Finally, the blocks were sintered at $700^{\circ} \mathrm{C}$ with a heating rate of $5^{\circ} \mathrm{C} / \mathrm{min}$ and a preservation time of $2 \mathrm{~h}$. Partially sintered porous blocks were infiltrated with Bis-GMA/TEGDMA (with a mass ratio of 50/50) and UDMA/TEGDMA (with a mass ratio of 80/20), respectively, and cured at $70^{\circ} \mathrm{C}$ for $8 \mathrm{~h}$. Dibenzoylperoxide, BPO (J\&K Scientific, Ltd.), was used as the thermoinitiator. Two PICNs were obtained, i.e., Bis-GMA/TEGDMA-infiltrated PICNs (PICN BTC) and UDMA/TEGDMA-infiltrated PICNs (PICN UTC).

A precision cutting machine loaded with a diamond saw was used to cut the bending bars $(2.2 \mathrm{~mm} \times 2.2 \mathrm{~mm} \times 20 \mathrm{~mm}$, $n=15)$ from corresponding composite blocks. Three groups of bars ( $2 \mathrm{~mm} \times 2 \mathrm{~mm} \times 20 \mathrm{~mm}$, with different roughness) for each material were fabricated by sanding the bars with $400 \#$ and 1500\# abrasive papers and polishing with a $0.5-\mu \mathrm{m}$ diamond suspension. Two scratch directions were exerted on each group, i.e., perpendicular and parallel to the bending span.

\section{Mid-infrared Spectroscopy Tests}

Fourier transform infrared spectroscopy were often used to characterize the conversion degree of dental composites. The Bis-GMA/TEGDMA and UDMA/TEGDMA monomers cured at $70^{\circ} \mathrm{C}$ for $8 \mathrm{~h}$ were tested with uncured monomers as control using mid-infrared spectroscopy. As for the Bis-GMA/TEGDMA group, there are peaks of around 1,608 $\mathrm{cm}^{-1}$ (aromatic 
C-C) and 1,637 $\mathrm{cm}^{-1}$ (aliphatic $\mathrm{C}=\mathrm{C}$ ) for both mid-infrared spectroscopies. As for the UDMA/TEGDMA group, there are peaks of around $1,537 \mathrm{~cm}^{-1}(\mathrm{~N}-\mathrm{H})$ and $1,637 \mathrm{~cm}^{-1}$ (aliphatic $\mathrm{C}=\mathrm{C})$. The 1,608 and $1,537 \mathrm{~cm}^{-1}$ peaks remain constant before and after polymerization, serving as internal standards. The percentage of unconverted $\mathrm{C}=\mathrm{C}$ bonds was calculated by comparing the intensity of the aliphatic $\mathrm{C}=\mathrm{C}$ peak at $1,637 \mathrm{~cm}^{-1}$ and the reference peak of polymer and monomer. DC were calculated from the results of both mid-infrared spectroscopies according to the following formula:

$\%$ conversion $=1-\frac{[\text { aliphatic }(C=C) / \text { reference }]_{\text {polymer }}}{[\text { aliphatic }(C=C) / \text { reference }]_{\text {monomer }}}$

\section{Surface Roughness Testing}

Roughness tests of sanded and polished specimens were performed using a profilometer (DektakXT, Bruker, Germany). The measurement was assessed with a scan length of $300 \mu \mathrm{m}$ and a scan time of $7 \mathrm{~s}$. The test direction was perpendicular to the scratch. Arithmetic mean deviation $(\mathrm{Pa})$ and root mean square deviation $(\mathrm{Pq})$ were calculated automatically by the system.

\section{Flexural Strength Testing}

The testing of flexural strength was carried out with a universal test machine (Shimadzu, EZ-100, Japan) in a three-point bending format. The maximum stress at fracture was calculated by the equation:

$$
\sigma_{f}=\frac{3 F l}{2 b d^{2}}
$$

Where $F$ is the maximum load at the point of fracture, $l$ is the distance of the roller span (here $1=10 \mathrm{~mm}$ ), $b$ is the width (here $2 \mathrm{~mm}$ ), and $h$ is the height (here $2 \mathrm{~mm}$ ) of the specimen. The loading speed was $0.75 \mathrm{~mm} / \mathrm{min}$.

Vickers hardness and elastic modulus were calculated from 10 nano-indentations for each PICN. The nano-indentations were carried out with a fixed depth of 1,000 nm using a nanoindentation tester (MTS, Keysight, G200, America).

\section{Observations of Surface and Inner Micro-structure}

Five Vickers indentations with a maximum load of $5 \mathrm{~kg}$ were exerted to highly polished surfaces of two PICNs and the dense ceramic counterparts using a hardness tester (Wilson Hardness, America). The samples were observed using SEM ( 2 IGMA HD Zeiss, Germany). Sodium aluminum silicate particles were observed using a transmission electron microscope (TEM). The characteristics of the cracks were compared, and the reinforcing mechanism of PICNs was evaluated.

\section{Statistics}

Flexural strength results were evaluated using single-factor ANOVA by SPSS with respect to $95 \%$ confidence interval. The flexural strength values were also analyzed using Weibull statistics according to the equation:

$$
\ln \ln \left(1 /\left(1-P_{i}\right)\right)=m \ln \sigma-m \ln \sigma_{0}
$$

Where $\sigma$ is flexural strength, $\sigma_{0}$ is the scale parameter or characteristic strength, and $m$ is the Weibull modulus. $P_{i}$ is the probability of failure, calculated according to the equation:

$$
P_{i}=(i-0.5) / N
$$

where $i$ is the $i$ th sample, and $N$ is the whole number of the samples in each group.

\section{RESULTS}

\section{Degree of Conversion}

Figure 1 shows the FTIR spectra of the Bis-GMA/TEGDMA and UDMA/TEGDMA monomers before and after polymerization.
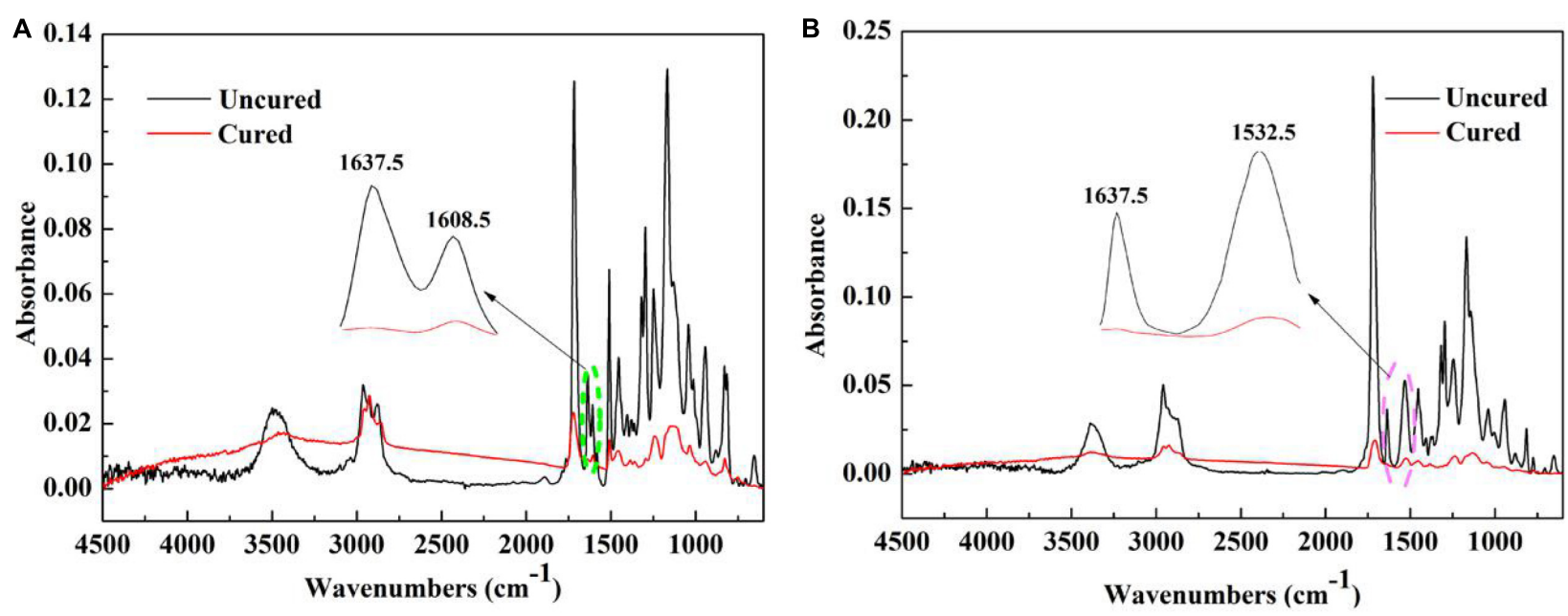

FIGURE 1 | Mid-infrared spectroscopy of uncured and cured pure resin. (A) Bis-GMA/TEGDMA, (B) UDMA/TEGDMA. 
After polymerization, decreases of the $\mathrm{C}=\mathrm{C}$ peak (around $1,640 \mathrm{~cm}^{-1}$ ) were notably observed in both FTIR spectroscopy.

The calculated DC values from the FITR results of BisGMA/TEGDMA and UDMA/TEGDMA are listed in Table $\mathbf{1 .}$ Both indicated a high polymerization degree.

\section{Transmission Electron Microscope Observations of Inorganic Particles}

The TEM observations (Figure 2) show the nano-cluster characteristic of the inorganic component. Each individual particle appeared to be spherical, with an average diameter of less than $100 \mathrm{~nm}$.

\section{Macroscopic and Microscopic Photographs of Two PICNs}

Figure 3 shows the photographs and SEM images of two PICNs, i.e., PICN BTC and PICN UTC. PICN UTC exhibited a higher transparency than PICN BTC. For PICN UTC, the background could be seen clearly through the composite. PICN BTC showed a translucent characteristic with a low light transmittance and an opalescent appearance.

\section{The Mechanical Properties of Two PICNs}

The mechanical properties of two PICNs are listed in Table 2. There were no significant differences between each other.

\section{The SEM Micrographs of Composites' Surface}

The SEM micrographs (Figures $\mathbf{4 a - f}$ ) of the composites' surfaces reveal evident unidirectional scratches (Figures $\mathbf{4 a}, \mathbf{b}, \mathbf{d}, \mathbf{e}$ ) after grinding with abrasive papers and smooth surfaces (Figures $\mathbf{4 c}, \mathbf{f}$ ) after polishing.

TABLE 1 | Degrees of conversion (DC) of Bis-GMATTEGDMA and UDMATTEGDMA specimens.

\begin{tabular}{lcc}
\hline Monomer mixture & Bis-GMA/TEGDMA & UDMA/TEGDMA \\
\hline Calculated DC (\%) & 81.9 & 81.7
\end{tabular}

\section{Surface Roughness Values}

The average roughness values of sanded and polished samples are presented in Table 3. The arithmetic mean deviation $(\mathrm{Pa})$ and root mean square deviation $(\mathrm{Pq})$ of PICN BTC varied from $11.5 \pm 7.9$ to $828.8 \pm 127.6 \mathrm{~nm}$ and from $14.2 \pm 9.4$ to $1,016.8 \pm 149.5 \mathrm{~nm}$, respectively. Those two values of PICN UTC varied from $18.7 \pm 17.1$ to $984.1 \pm 238.2 \mathrm{~nm}$ and from $23.7 \pm 20.9$ to $1,195.8 \pm 276.9 \mathrm{~nm}$, respectively. Slightly higher surface roughness values were produced for PICN UTC even for the same sanding or polishing procedure.

\section{Comparison of Flexural Strength}

The results of the flexural strength are shown in Figures 5A,B.

The flexural strengths of PICN BTC varied from $83.37 \pm 9.45$ to $140.24 \pm 7.65 \mathrm{MPa}$, while that of PICN UTC varied from $108.71 \pm 9.25$ to $156.26 \pm 9.52 \mathrm{MPa}$.

\section{Weibull Plots of Flexural Strength}

Weibull plots of flexural strength are shown in Figures 6A,B. The Weibull modulus showed an increasing trend with decrease of surface roughness for both PICN BTC and PICN UTC. A high Weibull modulus indicated a centralized degree of flexural strength values.

\section{Crack Propagation Observation of Ceramics and Two PICNs}

The indentation areas of ceramics and two PICNs at an indentation load of $50 \mathrm{~N}$ are shown in Figure 7. For ceramics, crack propagation from indentation diagonals was observed clearly (Figures 7a,b). For two PICNs, no cracks emanating from the diagonals were observed. Cracks could only be found under diamond indenter (Figures $7 \mathbf{c}, \mathbf{e}$ ). For the cracks under diamond indenter induced in the high-gloss-polished surfaces of two PICNs, crack bridging phenomenon was observed.

\section{DISCUSSION}

Dental composites have been developed rapidly in recent years. Ferracane (2011) gave a thorough classification about
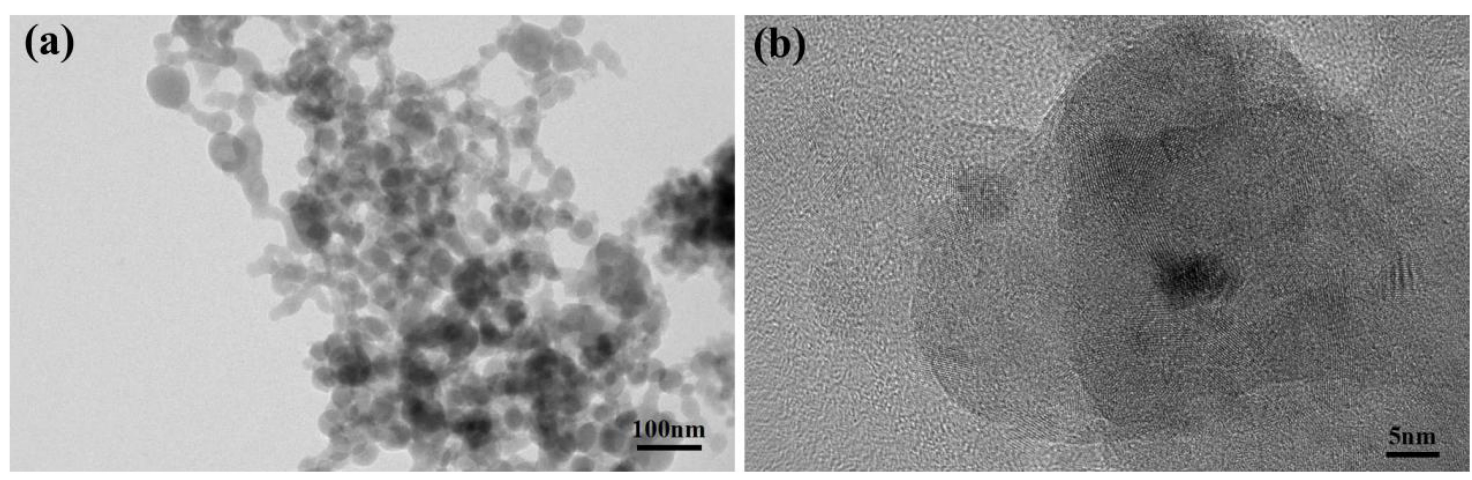

FIGURE 2 | Microstructures of sodium aluminum silicate nano-clusters. (a) TEM observations of the inorganic component. (b) Zoomed-in view of A. 

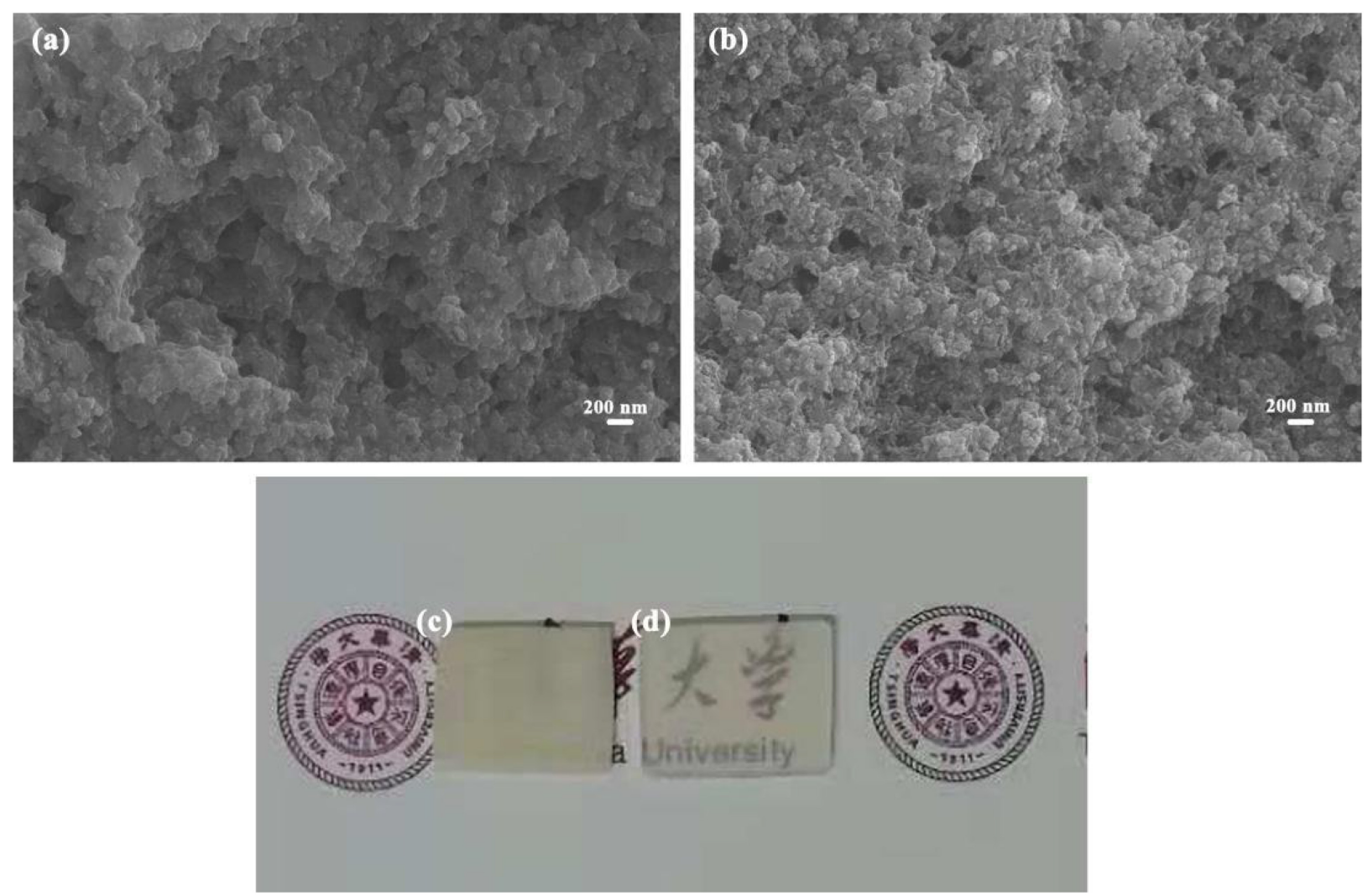

FIGURE 3 | Micro-structures and sample photographs of two PICNs. (a,c) PICN BTC, (b,d) PICN UTC.

TABLE 2 | Mechanical properties of two polymer-infiltrated ceramic network composites (PICNs).

\begin{tabular}{lccc}
\hline & $\begin{array}{c}\text { Flexural } \\
\text { strength } \\
\text { (MPa) }\end{array}$ & $\begin{array}{c}\text { Elastic } \\
\text { modulus } \\
\text { (GPa) }\end{array}$ & $\begin{array}{c}\text { Vickers } \\
\text { hardness } \\
\text { (GPa) }\end{array}$ \\
\hline PICN BTC & $140.24 \pm 7.65$ & $18.69 \pm 2.02$ & $1.198 \pm 0.090$ \\
PICN UTC & $156.26 \pm 9.52$ & $18.93 \pm 2.07$ & $1.209 \pm 0.097$ \\
\hline
\end{tabular}

conventional dental composites based on the characteristics of inorganic fillers. In the present study, a novel dental composite was fabricated, with its properties being evaluated. This novel composite was of a special structure. The TEM micrographs (Figures 2a,b) indicate sodium aluminum silicate with a nanocluster structure. Bis-GMA-based and UDMA-based composites are two main contemporary restorative options in either direct composite restorations or CAD/CAM composite blocks, and BisGMA/TEGDMA and UDMA/TEGDMA resin systems were used in this study. As for this novel restorative composite, the DC value can reach a very high level via thermal polymerization (Aljabo et al., 2015).

The ceramic components used in this work were different from the irregular micron ones used in VITA Enamic. As could be observed in Figure 2, the inorganic components are nanoclusters. Silica/zirconia nano-clusters have already been used as fillers in Lava Ultimate, with a high flexural strength obtained. Due to the characteristics of the particles, there is a complete infiltration of the monomer mixture into the partially sintered blocks. SEM observations of PICNs' microstructure indicate the thorough infiltration of polymer (Figures 3a,b). Increasing demands for esthetic restoration led the manufacturers to provide restorative composites with an appearance similar to that of natural tooth. Color match and transparency are two important criteria in esthetic dentistry. PICN BTC (Figure 3c) and PICN UTC (Figure 3d) exhibit an opalescent appearance and a high translucent characteristic, respectively. These performances are desirable, as they provide the ability to formulate a large range of colors to mimic the natural tooth. A highly translucent characteristic makes it resemble the appearance of natural enamel. The higher light transmission of PICN UTC than PICN BTC may be attributed to the close match of the refractive indices between silica and UDMA. Shade matching is a frustrating clinical process for direct light-cured restorative composites, as there exists color changes as a result of polymerization (Lee et al., 2003). Because of in vitro polymerization of PICNs, the color of dental composites is fixed and stabilized before restoration, and it does not pose the problems of color changes caused by polymerization.

As reported (Sakaguchi and Powers, 2012), the flexural strength, elastic modulus, and hardness of natural enamel were 60-90 $\mathrm{MPa}, 60-120 \mathrm{GPa}$, and 3-6 GPa, respectively; 

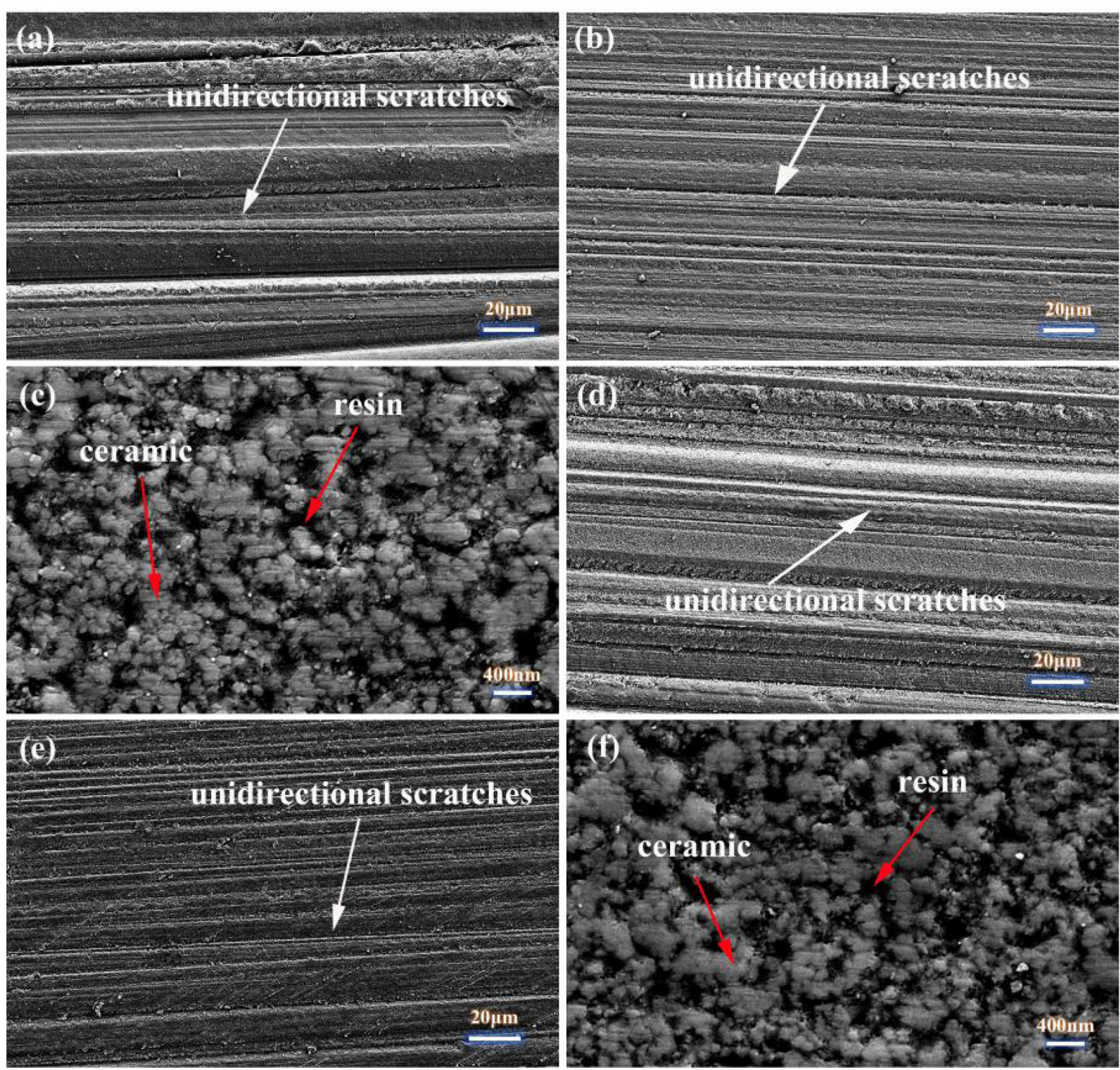

FIGURE 4 | Microstructures of sanded and polished surfaces of composites. (a) 400\# sanded PICN BTC. (b) 1500\# sanded PICN BTC. (c) Polished PICN BTC. (d) 400\# sanded PICN UTC. (e) 1500\# sanded PICN UTC. (f) Polished PICN UTC.

TABLE 3 | Surface roughness values of sanded and polished samples.

\begin{tabular}{|c|c|c|c|c|c|c|}
\hline Material & \multicolumn{2}{|c|}{$400 \#$ sanded } & \multicolumn{2}{|c|}{ 1500\# sanded } & \multicolumn{2}{|c|}{ Polished } \\
\hline PICN BTC & $828.8 \pm 127.6$ & $1,016.8 \pm 149.5$ & $138.6 \pm 64.6$ & $172.2 \pm 87.6$ & $11.5 \pm 7.9$ & $14.2 \pm 9.4$ \\
\hline PICN UTC & $984.1 \pm 238.2$ & $1,195.8 \pm 276.9$ & $325.5 \pm 143.2$ & $395.5 \pm 162.1$ & $18.7 \pm 17.1$ & $23.7 \pm 20.9$ \\
\hline
\end{tabular}

those values of natural dentin were 245-280 MPa, 18-24 GPa, and 0.13-0.92 GPa (Mahoney et al., 2000). The mechanical properties of two PICNs are listed in Table 2. The flexural strength values (140.24 and $156.26 \mathrm{MPa}$ ) of two PICNs were between that of natural enamel and natural dentin. The high flexural strength of PICNs may be attributed to the unique structure of this kind of material. The tested Vickers hardness values were 1.198 and $1.209 \mathrm{GPa}$, respectively, very close to that of natural dentin $(0.13-0.92 \mathrm{GPa})$. The elastic modulus (18.69 and $18.93 \mathrm{GPa}$ ) of these two PICNs resembles that of natural dentin (18-24 GPa). It is the goal of dental material research to achieve a similarity of the mechanical properties of 

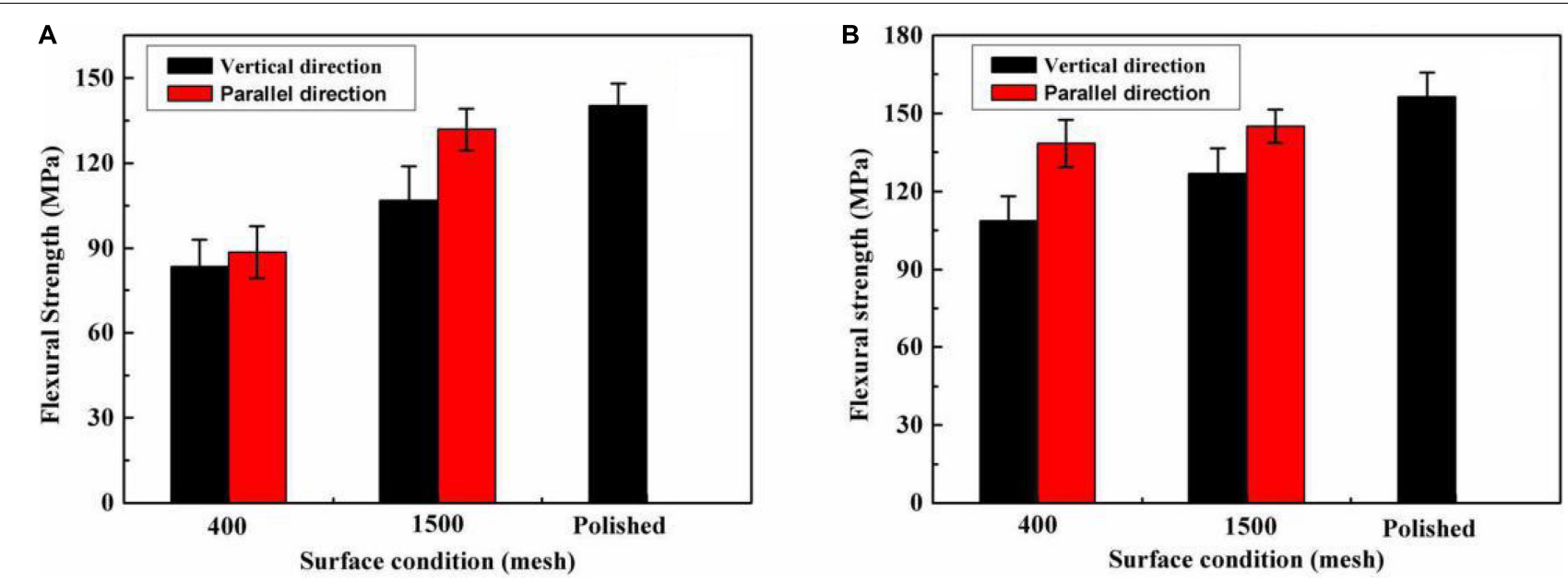

FIGURE 5 | Results of flexural strength of polymer-infiltrated ceramic networks (PICNs) with respect to surface condition. (A) PICN BTC which were sanded and polished with 400\# and 1500\# abrasive paper. (B) PICN UTC which were sanded and polished with 400\# and 1500\# abrasive paper.
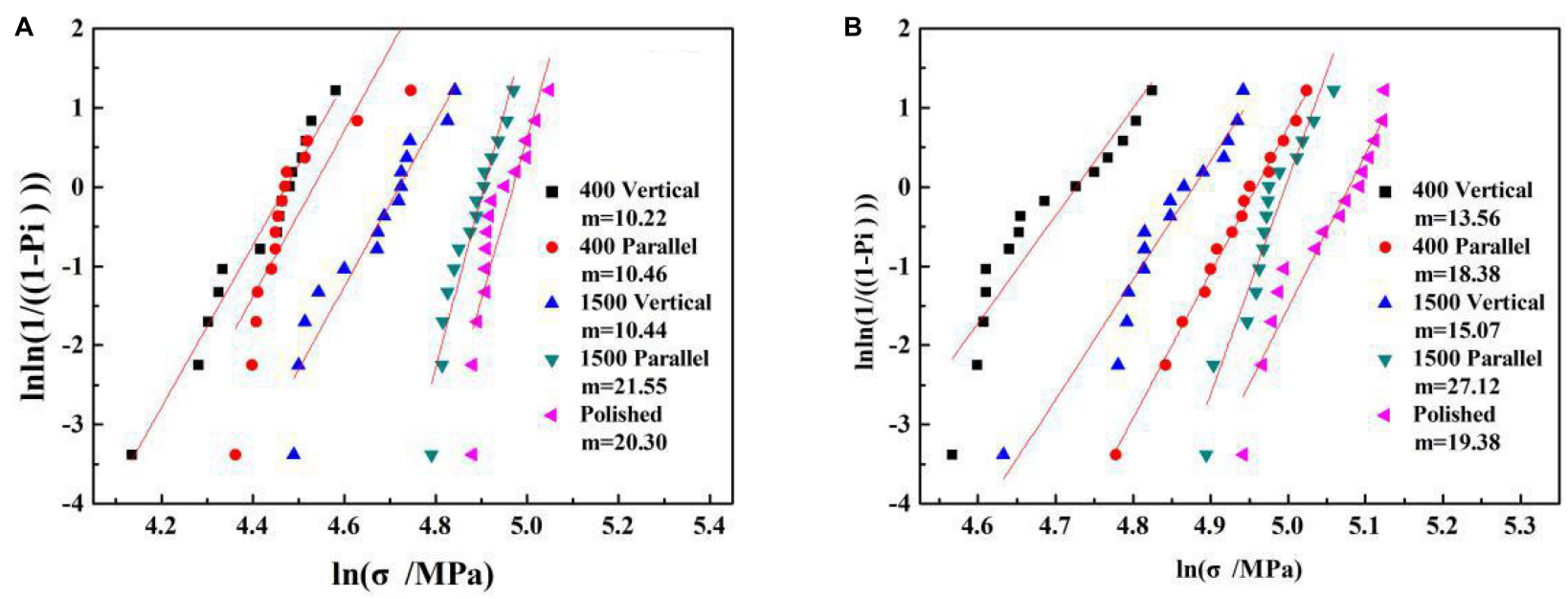

FIGURE 6 | Weibull plots of flexural strength of PICN BTC in panel (A) and PICN UTC in panel (B).

restorative materials to that of natural enamel and dentin. The characteristics of moderate hardness and elastic modulus may be of considerable advantage, as the wear of the antagonist could be avoided.

Dental restoration involves many processes. The processing procedures during clinical adjustment, i.e., cutting, machining, grinding, polishing, sandblasting, etc., could have potential effects on the loss of strength (Al-Haj Husain et al., 2016; Curran et al., 2017; Hatanaka et al., 2017; Mohammadi-Bassir et al., 2017). Dental restorative materials are adjusted in the complicated oral environment. The surface roughness of dental materials could be affected by physical and chemical factors such as wear, food, tooth brushing, and temperature change (Da Costa et al., 2010; Heintze et al., 2010; Roselino et al., 2013, 2015; Kamonkhantikul et al., 2016). Previous studies showed that many factors could induce the increase of surface roughness which could decrease the flexural strength of restorative composites (Da Costa et al.,
2010; Coldea et al., 2013; Belli et al., 2014; Al-Harbi et al., 2017). The composites used for CAD/CAM must be shaped to a final size via material removal before being adjusted to the areas to be restored. Sanding with abrasive paper may be an available method to produce unidirectional scratches, as shown in Figures 1C,D,F,G. Sanding the samples with different abrasive paper and polishing could produce a significantly different surface roughness at $p<0.05$ (Table 1). For either vertical types or parallel types, the flexural strength increased with the decrease of surface roughness. The source of failure may be located at the extrinsic defects (flaws or surface cracks) in the unidirectional scratches.

The flexural strength values were compared among groups of different roughness values and defect directions. The null hypothesis was rejected as significant differences were observed for the same surface roughness values with different defect directions. 


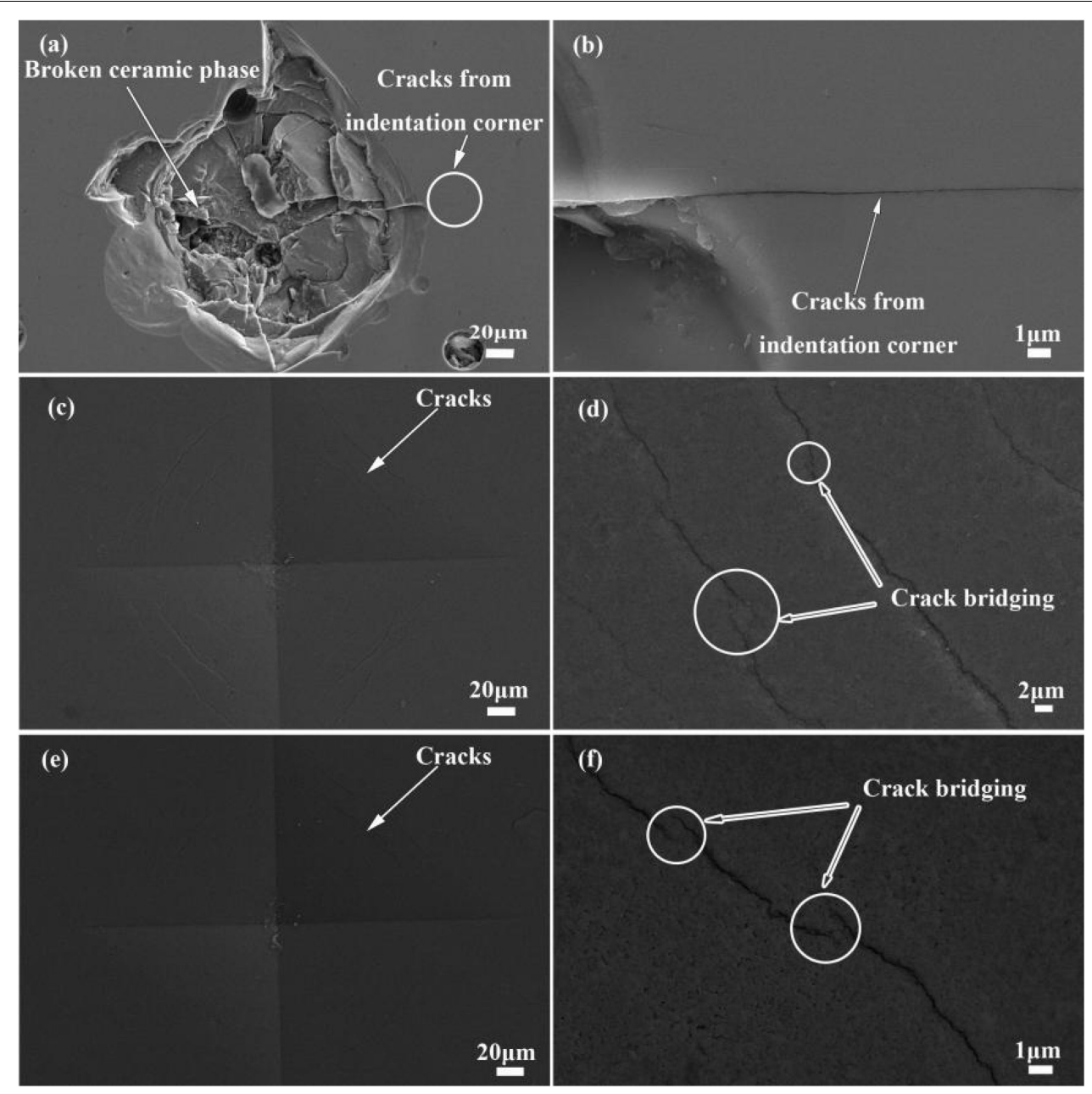

FIGURE 7 | Scanning electron microscope of indentation areas of ceramics and PICNs at an indentation load of 50 N. (a,b) Ceramic, (c,d) PICN BTC, and (e,f) PICN UTC.

As for PICN BTC, the effects of roughness and scratch directions on flexural strength could be observed. When the samples were sanded with $400 \#$ abrasive paper, there were no significant differences $(p=1)$ between vertical types and parallel types. When the samples were sanded with $1500 \#$ abrasive paper, the flexural strength of parallel types $(131.77 \pm 7.28 \mathrm{MPa})$ was significantly higher than that of vertical types $(106.95 \pm 11.93 \mathrm{MPa})$ at $p<0.05$. There were even no significant differences between that of samples sanded with 1500\# abrasive paper (parallel type) and that of thoroughly polished samples, although the roughness of the former $(\mathrm{Pa}=311.86 \mathrm{~nm}$ and $\mathrm{Pq}=366.89 \mathrm{~nm}$ ) is obviously larger than that of the latter $(\mathrm{Pa}=11.76 \mathrm{~nm}$ and $\mathrm{Pq}=17.71 \mathrm{~nm})$. As for PICN UTC, similar effects could also be observed. The scratch directions of sample surfaces could affect the flexural strength significantly for both $400 \#$ and $1500 \#$ abrasive paper-sanded samples at $p<0.05$. The differences between the flexural strength of samples sanded with 1500\# abrasive paper (parallel type) and that of polished samples could also be seen as significant at $p=0.009$.
There was an increasing trend of Weibull modulus with the decrease of surface roughness (Figure 3). A low Weibull modulus indicates that there exists a big variation in surface appearance and an inhomogeneous microcrack density as suggested in some research in zirconia (Luthardt et al., 2002; Wang et al., 2008; Hatanaka et al., 2017). Sanding with higher-mesh abrasive papers or polishing could contribute to less and homogeneous microcrack dentistry, leading to higher values of Weibull modulus or a lower scatter of flexural strength values. According to the Weibull plots of flexural strength (Figure 6), the reliability of dental composites could be increased via thorough polishing.

No previous investigations were found in literature about the effects of scratch direction on flexural strength. The observations from this study suggest that this factor plays an important role in the flexural strength of dental composites. The flexural strength of parallel types was significantly higher than that of vertical types, with nearly the same surface roughness for most of the data. There existed more micro-cracks perpendicular to tensile stress, leading to the fracture of materials at a relatively low stress for vertical types. The Weibull modulus values were higher 
for parallel types than for vertical types even with nearly the same surface roughness. These results indicate that the failure of restorative composites occurs with a high probability in the direction perpendicular to the force for the same roughness value.

The mechanical properties are all attributed to the unique structure. The reinforcing mechanisms of PICNs were observed by comparing the crack propagation to that of dense ceramic after indention (Figure 7). The crack bridging observed in PICNs indicates an enhanced resistance to crack propagation. This performance was also interpreted as R-curve (resistance curve) behavior (Swain et al., 2016). In PICNs, the constituent ceramic phase and polymer phase are mutually interconnected with each other in a three-dimensional topological structure. This unique structure enables the reinforcement phase to distribute stresses introduced to PICNs. Polymer, which plays the part of the reinforcing phase, offers effective resistance to crack propagation via crack bridging. This structural feature endows PICNs with an insensitive property to microcracks.

\section{CONCLUSION}

This paper has focused on the fabrication of a novel restorative composite and its characterization. The effects of surface roughness on the flexural strength of experimental PICNs were evaluated. The surface with different roughness values were produced by sanding with abrasive paper and polishing. The results indicated that both the surface roughness value and scratch directions affected the flexural strength. A large roughness

\section{REFERENCES}

Acar, O., Yilmaz, B., Altintas, S. H., Chandrasekaran, I., and Johnston, W. M. (2016). Color stainability of CAD/CAM and nanocomposite resin materials. J. Prosthet. Dent. 115, 71-75. doi: 10.1016/j.prosdent.2015.06.014

Al-Haj Husain, N., Camilleri, J., and Özcan, M. (2016). Effect of polishing instruments and polishing regimens on surface topography and phase transformation of monolithic zirconia: An evaluation with XPS and XRD analysis. J. Mech. Behav. Biomed. 64, 104-112. doi: 10.1016/j.jmbbm.2016.07. 025

Alharbi, A., Ardu, S., Bortolotto, T., and Krejci, I. (2017). Stain susceptibility of composite and ceramic CAD/CAM blocks versus direct resin composites with different resinous matrices. Odontology. 105, 162-169. doi: 10.1007/s10266016-0258-1

Al-Harbi, F. A., Ayad, N. M., ArRejaie, A. S., Bahgat, H. A., and Baba, N. Z. (2017). Effect of Aging Regimens on Resin Nanoceramic Chairside CAD/CAM Material. J. Prosthodont. 26, 432-439. doi: 10.1111/jopr.12408

Aljabo, A., Xia, W., Liaqat, S., Khan, M. A., Knowles, J. C., Ashley, P., et al. (2015). Conversion, shrinkage, water sorption, flexural strength and modulus of remineralizing dental composites. Dent. Mater. 31, 1279-1289. doi: 10.1016/j. dental.2015.08.149

Belli, R., Geinzer, E., Muschweck, A., Petschelt, A., and Lohbauer, U. (2014). Mechanical fatigue degradation of ceramics versus resin composites for dental restorations. Dent. Mater. 30, 424-432. doi: 10.1016/j.dental.2014.01.003

Coldea, A., Swain, M. V., and Thiel, N. (2013). In-vitro strength degradation of dental ceramics and novel PICN material by sharp indentation. J. Mech. Behav. Biomed. 26, 34-42. doi: 10.1016/j.jmbbm.2013.05.004

Curran, P., Cattani-Lorente, M., Anselm Wiskott, H. W., Durual, S., and Scherrer, S. S. (2017). Grinding damage assessment for CAD-CAM restorative materials. Dent. Mater. 33, 294-308. doi: 10.1016/j.dental.2016.12.004 value and a scratch direction perpendicular to tensile stress are detrimental to PICNs. It is suggested that these factors should be taken into consideration during clinical process. The reinforcing mechanism was analyzed. The fabricated PICNs with a unique structure may be a promising candidate for dental restoration.

\section{DATA AVAILABILITY STATEMENT}

The original contributions presented in the study are included in the article/supplementary material, further inquiries can be directed to the corresponding author.

\section{AUTHOR CONTRIBUTIONS}

YL: conceptualization, project administration, resources, and supervision. LZ: formal analysis. YL and $\mathrm{HW}$ : funding acquisition. BC, YS, ML, XD, and CN: methodology. QD and LZ: software. BC: writing - original draft. BC and FS: writing review and editing. All authors discussed the results.

\section{FUNDING}

This work was financially supported by Beijing Municipal Science and Technology Commission (No. Z171100002017009), National Natural Science Foundation of China (No. 51972240) and National Science Foundation (51532003, 51221291, 51328203, and 81671026).

Da Costa, J., Adams-Belusko, A., Riley, K., and Ferracane, J. L. (2010). The effect of various dentifrices on surface roughness and gloss of resin composites. J. Dent. 38, e123-e128. doi: 10.1016/j.jdent.2010.02.005

Denry, I., and Kelly, J. R. (2008). State of the art of zirconia for dental applications. Dent. Mater. 24, 299-307. doi: 10.1016/j.dental.2007.05.007

Feng, L., and Suh, B. I. (2006). The effect of curing modes on polymerization contraction stress of a dual cured composite. J. Biomed. Mater. Res. B: Appl. Biomater. 76, 196-202.

Ferracane, J. L. (2011). Resin composite-State of the art. Dent. Mater. 27, 29-38. doi: 10.1016/j.dental.2010.10.020

Ferracane, J. L., and Greener, E. H. (1986). The effect of resin formulation on the degree of conversion and mechanical properties of dental restorative resins. J. Biomed. Mater. Res. 20, 121-131. doi: 10.1002/jbm.820200111

Hatanaka, G. R., Polli, G. S., Fais, L. M. G., Reis, J. M. D. S., and Pinelli, L. A. P. (2017). Zirconia changes after grinding and regeneration firing. J. Prosthet. Dent. 118, 61-68. doi: 10.1016/j.prosdent.2016.09.026

He, L., and Swain, M. (2011). A novel polymer infiltrated ceramic dental material. Dent. Mater. 27, 527-534. doi: 10.1016/j.dental.2011.02.002

Heintze, S. D., Forjanic, M., Ohmiti, K., and Rousson, V. (2010). Surface deterioration of dental materials after simulated toothbrushing in relation to brushing time and load. Dent. Mater. 26, 306-319. doi: 10.1016/j.dental.2009. 11.152

Kamonkhantikul, K., Arksornnukit, M., Lauvahutanon, S., and Takahashi, H. (2016). Toothbrushing alters the surface roughness and gloss of composite resin CAD/CAM blocks. Dent. Mater. J. 35, 225-232. doi: 10.4012/dmj.2015-228

Klapdohr, S., and Moszner, N. (2005). New inorganic components for dental filling composites. Monatsh. Chem. 136, 21-45. doi: 10.1007/s00706-004-0254-y

Lawson, N. C., Janyavula, S., Syklawer, S., McLaren, E. A., and Burgess, J. O. (2014). Wear of enamel opposing zirconia and lithium disilicate after adjustment, polishing and glazing. J. Dent. 42, 1586-1591. doi: 10.1016/j.jdent.2014.09.008 
Lee, Y., Lim, B., and Kim, C. (2003). Difference in polymerization color changes of dental resin composites by the measuring aperture size. J. Biomed. Mater. Res. B: Appl. Biomater. 66B, 373-378. doi: 10.1002/jbm.b.10034

Li, R. W. K., Chow, T. W., and Matinlinna, J. P. (2014). Ceramic dental biomaterials and CAD/CAM technology: State of the art. J. Prosthodont. Res. 58, 208-216.

Luthardt, R. G., Holzhüter, M., Sandkuhl, O., Herold, V., Schnapp, J. D., Kuhlisch, E., et al. (2002). Reliability and properties of ground Y-TZP-Zirconia ceramics. J. Dent. Res. 81, 487-491. doi: 10.1177/154405910208100711

Mahoney, E., Holt, A., Swain, M., and Kilpatrick, N. (2000). The hardness and modulus of elasticity of primary molar teeth:an ultra-micro-indentation study. J. Dent. 28, 589-594. doi: 10.1016/S0300-5712(00)00043-9

Mitra, S. B., Wu, D., and Holmes, B. N. (2003). An application of nanotechnology in advanced dental materials. J. Am. Dent. Assoc. 134, 1382-1390. doi: 10.14219/ jada.archive.2003.0054

Miyazaki, T., Nakamura, T., Matsumura, H., Ban, S., and Kobayashi, T. (2013). Current status of zirconia restoration. J. Prosthodont. Res. 57, 236-261. doi: 10.1016/j.jpor.2013.09.001

Mohammadi-Bassir, M., Babasafari, M., Rezvani, M. B., and Jamshidian, M. (2017). Effect of coarse grinding, overglazing, and 2 polishing systems on the flexural strength, surface roughness, and phase transformation of yttrium-stabilized tetragonal zirconia. J. Prosthet. Dent. 118, 658-665. doi: 10.1016/j.prosdent. 2016.12.019

Moszner, N., and Salz, U. (2001). New developments of polymeric dental composites. Prog. Polym. Sci. 26, 535-576. doi: 10.1016/S0079-6700(01) 00005-3

Roselino, L. D. M. R., Chinelatti, M. A., Alandia-Román, C. C., and Pires-de-Souza, F. D. C. P. (2015). Effect of brushing time and dentifrice abrasiveness on color change and surface roughness of resin composites. Braz. Dent. J. 26, 507-513.

Roselino, L. D. M. R., Cruvinel, D. R., Chinelatti, M. A., and Pires-de-Souza, F. D. C. P. (2013). Effect of brushing and accelerated ageing on color stability and surface roughness of composites. J. Dent. 41, e54-e61. doi: 10.1016/j.jdent. 2013.07.005

Rueggeberg, F. A. (2011). State-of-the-art: Dental photocuring-a review. Dent. Mater. 27, 39-52. doi: 10.1016/j.dental.2010.10.021

Sakaguchi, R. L., and Powers, J. M. (2012). “The Oral Environment," in Craig's Restorative Dental Materials, 13th Edn, (Saint Louis, MO: Mosby). ${ }^{* *} \mathrm{Q}$.

Silva Prezotto, A. F., Silva, D. B., Vitti, R. P., Sinhoreti, M. A. C., and Brandt, W. C. (2018). Light curing and ratio of glass/fumed silica fillers on degree of conversion and mechanical properties of experimental composite resins. J. Appl. Polym. Sci. 136, 47008. doi: 10.1002/app.47008

Swain, M. V., Coldea, A., Bilkhair, A., and Guess, P. C. (2016). Interpenetrating network ceramic-resin composite dental restorative materials. Dent. Mater. 32, 34-42. doi: 10.1016/j.dental.2015.09.009

Thornton, I. (2014). Mechanical properties of dental resin composite CAD/CAM blocks. Master of science. Vancouver, BC: The University of British Columbia.

Wang, H., Aboushelib, M. N., and Feilzer, A. J. (2008). Strength influencing variables on CAD/CAM zirconia frameworks. Dent. Mater. 24, 633-638. doi: 10.1016/j.dental.2007.06.030

Conflict of Interest: The authors declare that the research was conducted in the absence of any commercial or financial relationships that could be construed as a potential conflict of interest.

Copyright (C) 2021 Cui, Sun, Ding, Wang, Lin, Shen, Li, Deng, Zhang and Nan. This is an open-access article distributed under the terms of the Creative Commons Attribution License (CC BY). The use, distribution or reproduction in other forums is permitted, provided the original author(s) and the copyright owner(s) are credited and that the original publication in this journal is cited, in accordance with accepted academic practice. No use, distribution or reproduction is permitted which does not comply with these terms. 